\title{
Assessment For Children's Values: Picture-Based Value Survey for Children Adaptation Study
}

\author{
Necla ACUN KAPIKIRAN¹, Aysun GÜNDOĞAN²
}

\begin{tabular}{l} 
ARTICLE INFO \\
\hline Article History: \\
Received 14.11.2017 \\
Received in revised form \\
19.01.201. \\
Accepted \\
Available online \\
01.04.2018
\end{tabular}

\begin{abstract}
The aim of the current study is to adapt the Picture-Based Value Survey for Children (PBVS-C) to Turkish in order to determine the values of elementary school level children. The participants were students from three different schools, age group of 7-12 (573 students: 270 (47\%) male and 303 (53\%) female). The Picture-Based Value Survey for Children (PBVS-C) was used to measure children's values. Multi-dimensional Scaling analyses (MDS) was used to create the model. The data analysis showed that the scale being developed based on Schwartz's theoretical model featured different dimensions for some of the values; e.g. different results were obtained for the "universalizm" dimension. Children make moral judgements from the very early periods of their lives, so their values begin to develop at quite early ages.
\end{abstract}

(C) 2018 IJERE. All rights reserved

Keywords:

Values, Schwartz's values model, school age children, survey, multi-dimensional scaling.

\section{INTRODUCTION}

Studies on the values of different age groups have recently started to attract more attention. Values are beliefs associated with the one's emotions. Values are considered as principles that lead to relatively significant behaviours by a certain standard which directs behaviour in order to achieve the desired goals (Schwartz, 2009). According to Schwartz (1999), values are determined with three universal realities. These realities are associated with satisfying the needs of the biological organism, the fact of the coordinated social interactions and survival and well-being of the group. Moreover, the individual should fulfil his interaction with other people co-ordinately as well as satisfying his biological needs and act to contribute to the future of his kind while performing all of the above-mentioned actions. While these realities interact with the child's family, school, groups, and mass media in the process of socialization of the child, the child is affected by cultural or universal values in this interaction. Schwartz $(1992,1994,2009)$ classified the values as four upper level categories and ten different dimensions. While subjective values are directed to openness to change (self-directed, stimulation and hedonism) and self-enhancement (pleasure, achievement and power) in the classification of values of Schwartz (1992, 1994, 2009), social values are associated with selftranscendence (universalism, benevolence) and conservation (conformity, tradition and security). It is reported in many studies that openness to change value opposes values of conservation and selftranscendence value opposes values of self-enhancement (Schwartz, 1992, 1994, 2009; Schwartz, Melech, Lehmann, Burgess, Harris \& Owens, 2001).

\footnotetext{
${ }^{1}$ Pamukkale University, Faculty of Education, Department of Educational Sciences, Guidance and Counseling, 20070 Pamukkale, Denizli, Turkey. E-mail: nkkiran@pau.edu.tr, orcid.org/0000-00033971-4644

2 Pamukkale University, Tavas Vocational School of Higher Education, Child Care and Youth Services Department, Child Development Program, Denizli, Turkey. E-mail:aysungundogan@yahoo.com Corresponding e-mail: nkkiran@ pau.edu.tr, orcid.org/ 0000-0002-9521-1577
} 


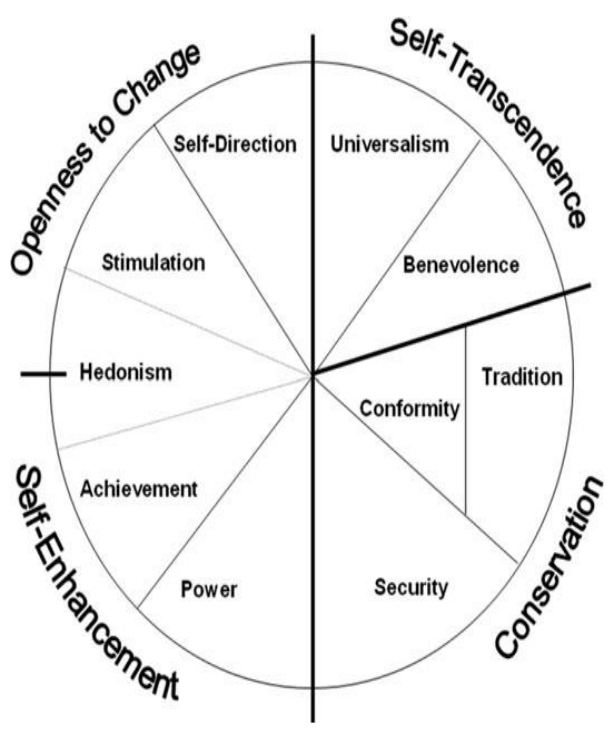

Figure 1. Schwartz (1994)'s value types

Table 1. Motivational value types (see, e.g., Schwartz, 1992, 1994:22) value Types (and Items) central motivational goal.

1. Universalism UN Understanding, appreciation, (tolerance, and protection for the welfare of all people and for nature

2. Benevolence BE Preservation and enhancement of (BE1, BE2) the welfare of people with whom one is in frequent personal contact.

3. Tradition TR Respect, commitment, and acceptance of (TR1, TR2) the customs and ideas that traditional culture or religion provide.

4. Conformity CO Restraint of actions, inclinations, and(CO1, CO2) impulses likely to upset or harm others and violate social expectations or norms

5. Security SE Safety, harmony, and stability of society, (SE1, SE2) of relationships, and of self.

6. Power PO Social status and prestige, control or (PO1, PO2) dominance over people and resources

7. Achievement AC Personal success through demonstrating (AC1, AC2) competence according to social standards.

8. Hedonism HE Pleasure and sensuous (HE1, HE2) gratification for oneself.

9. Stimulation ST Excitement, novelty, and (ST1, ST2) challenge in life

10. Self-Direction (SD) Independent thought and action (SD1,SD2)choosing, creating, exploring (creativity, curious, freedom)

Values of self-transcendence (benevolence and universalism) cause anxiety at a macro level because these values include concerns regarding the future of the society and the world. (Schwartz, Sagiv \& Boehnke, 2000). These values comprise the values of self-enhancement that are associated with the need for growth and away from anxieties (Schwartz, 2006).

Again, openness to change (self-direction, stimulation and hedonism) that is independent of social and individual anxiety is individualistic and it leads the individual to achieve the goal at hand. However, conservative values (tradition, conformity and security) that contain rather individual and social concerns are classified as social values for protecting self against threats (Schwartz, 2006). Again, values for selfenhancement (power, achievement) are classified as individual values that created anxiety at micro level (Schwartz, et al., 2000) and intended to prevent the loss of target and caused anxiety (Schwartz, 2006). While children learn about how to interact with other people in the family, some principles begin to accompany their behaviours. The fact that parents share their own principles with their children lead children to learn how they should act according to the situation. In this case, while parents share the principles which accompany their behaviours with their children, they should take children's perspectives on these principles 
into consideration. At the same time, a certain logical inference by parents on these principles provides an important transfer of these principles from parents to children (Knafo \& Assor, 2007).

Perception and acceptance of parents' principles accurately by their children are associated with congruence between the values (Knafo, 2003; Knafo \& Schwartz, 2001; Knafo \& Schwartz, 2003). While this congruence is observed in young people who perceive their parents warmly, it causes a conflict between the values of young people who perceive their parents more authoritarian (Knafo \& Schwartz, 2003; Wray-Lake, Flanagan \& Maggs, 2012). At the same time, the fact that parents prefer schools that are congruent with their own values is accompanied by the congruence of the family and the environment in children's socialization (Knafo, 2003). It is reported that genetic and environmental factors are effective in the emergence of values in children, girls have low levels of self-transcendence values and the reason for these values to be higher in males is due to shared environment rather than genetic characteristics (Knafo \& Spinath, 2011). At the same time, the fact that parents prefer schools that are congruent with their own values are accompanied by congruence of the family and the environment in children's socialization (Knafo, 2003).

The children's correct preceiving of and acceptance of parents'principles depend on the agreement of values (Knafo, 2003; Knafo \& Schwartz, 2001; Knafo ve Schwartz, 2003).It is reported that genetic and environmental factors are effective in the emergence of values in children, females have low levels of selftranscendence values and the reason for these values to be higher in males is due to shared environment rather than genetic characteristics (Knafo \& Spinath, 2011).

Conformity between the values of children and parents increases self-esteem in children (Knafo \& Assor, 2007; Nunner-Winkler, 2007), both positive social behaviours (Laible, Eye \& Carlo, 2008, PadillaWalker, 2007) and the status of successful identification in young people (Knafo \& Schwartz, 2004). Moreover, values of self-enhancement reduces extraversion (Balliet, Joiremon, Daniels \& George-Falvy, 2008) while increasing empathy (Bilsky \& Schwartz, 1994).

In a study conducted with students and teachers from 56 countries, values of benevolence, selfdirection and universalism were observed to be as the most important values; power, tradition, stimulation as the least important values and values of safety, conservative and achievement and hedonism as the secondary important values (Schwartz and Bardi, 2001). Schwartz \& Rubel-Lifschitz, (2009) a study that included 25 countries found that while benevolence and universalism values were high in female participants; power, achievement and hedonism values were high in male participants. Similar findings were found in other studies as well (Casas, Figuer, Gonzales \& Malos, 2007; Dilmaç, Deniz \& Deniz, 2009; Yılmaz, Avşaroğlu \& Deniz, 2010).

Another dimension that needs to be taken into consideration in value studies is related to which of the values are universal and which are culture specific. In crosscultural studies there are a lot of studies that confirm Schwart's (1994) Values Model is universally valid (Schwartz \& Sagie, 2000; Schwartz \& Bardi, 2001). Although these values are valid for all cultures diffeent cultures may value different values. For instance, Americans value freedom, Australians value honesty, Finnish value being cheerful, and Spanish value freedom and achievement (Schwartz \& Bilsky, 1990). In other words, the meaning of the values can change according to the culture (Struch, Schwartz \& van der Kloot, 2002). There could be various factors for this meaningful change. One of them could be the spoken language (Davidov \& De Beuckelaer, 2010). Another factor could be the individual educational differences of children during the process of socialization. Educational differences could vary in different ethnic groups, different region and cities and families. For instance, while in Western Regions of Turkey individualistic values are emphasized (Göregenli, 1995), individualsin Eastern Regions of Turkey may have more of collectivist values. In other words, it could be said that the Turkish society has a relational autonomous structure (Kağıtçıbaşı, 1996) or a society with both individualistic and collectivist components (İmamoğlu, 2003).

Nevertheless, another factor that affect changes in values is age and age periods (Schwartz, 2006). Value studies including age range and age period studies in the literature are more related to middle childhood (Bubeck \& Bilsky, 2004; Döring, 2008, 2010; Döring, Blauensteiner, Aryus, Drögekamp \& Bilsky, 2010; Knafo \& Spinath, 2011), adolsecence and young adulthood (Casas, et al., 2007; Dirilen, 2006; Laible, et al., 2008, Padilla-Walker, 2007;) and adulthood (Schwartz \& Bardi, 2001; Schwartz, et al., 2001).However, values 
studies in Turkey only involved adolescence, young adulthood and adulthood (Dirilen, 2006; Gümüş, 2009; İmamoğlu \& Katipoğlu-Akgün, 2004; Yılmaz, Avşaroğlu \& Deniz, 2010).Values develop in earlier years of children, thus there is need to learn about values starting from middle childhood period and a scale that will measure these values. The existance of such a scale will provide to make new researches. Moreover, it may lead to understand and why values change overtime. In the light of previous research and literature, the aim of the current study is to adapt the Picture-Based Value Survey for Children (PBVS-C)(Döring, 2008) to Turkish in order to determine the values of elementary school level children.

\section{METHOD}

\section{Participants}

The participants of the study were elementary level students from three different schools in Denizli. The schools were chosen from three different residential areas in the province of Denizli. A total of 573 students were reached under the study. $270(47 \%)$ of the students were male and $303(53 \%)$ of them were female. The students' ages ranged from 7 to 11 (X:9.57, SD: 1.31). $13 \%$ of the students was the first-grade, $13 \%$ second-grade, $24 \%$ third grade, $24 \%$ fourth-grade and $26 \%$ fifth grade students. When the students' parents education periods were investigated, the average school utilization periods of the parents was found as 9 to 10 years.

\section{Measurements}

The Picture-Based Value Survey for Children (PBVS-C), developed by Döring (2008), was used. The scale contained 20 pictures developed for children aged 7 to 11 based on Schwartz's values model. According to the values model, there are two pictures available for each value for the classification of 10 values. Expert opinions were obtained for the scale's construct validity. Then, the children were asked to evaluate the pictures through the focus group discussion with the children. The children's evaluations were compared to the expert judgements. With these results, the content validity were examined. Then again, the construct validity of the scale was assessed applying the Multi-dimensional Scaling (MDS). The test was performed two times at two-week intervals for re-test reliability, and no structural change has been reported. Again, test - re-test reliability ranged between .50 and 1.00 with the Q-correlation and the average internal correlation was calculated as $.80(\mathrm{Sd}=11)$.

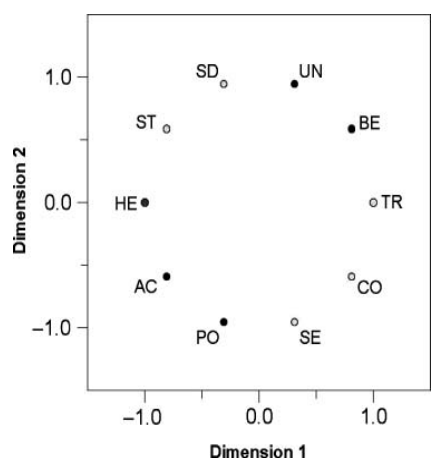

Figure 2. Starting configuration for the multidimensional scaling analyses.

$\mathrm{UN}=$ universalism, $\mathrm{BE}=$ benevolence, $\mathrm{TR}=$ tradition, $\mathrm{CO}=$ conformity, $\mathrm{SE}=$ security, $\mathrm{PO}=$ power, $\mathrm{AC}=$ achievement, $\mathrm{HE}=$ hedonism, $\mathrm{ST}=$ stimulation and $\mathrm{SD}=$ self-direction .

\section{Procedure}

Pilot Study 1. The Picture-Based Value Survey for Children (PBVS-C) was applied to 38 students (male: 19 and female: 19) from first to fifth grades. The students' ages ranged from 7 to $11(\mathrm{M}=8.5, \mathrm{Sd}=1.20)$. First of all, without any information about any of the values, participants were posed questions such as "what do you see in each picture, what is happening here, what is the hero doing in the picture, what is important to the hero". According to Table-1, each correct answer given by children was scored 1 point and each answer 
inconsistent with the pictures was scored 0 point. According to Schwartz's values model, it was understood that the pictures for the 19 values were perceived correctly by children in line with the classification in Table1 considering the data obtained. Only the picture TR-1 'thinking about God' was described differently (for example: they are eating, lights are off...). Döring (2008) reported that children in our country used the descriptions of they are eating, lights are off, they are sitting, power is cut and so on while Turkish children living in Germany described this picture correctly. They failed to correctly describe the picture because they did not have any experience on "thinking about God" in a different religion. Some survey items was given the below.

Tradition

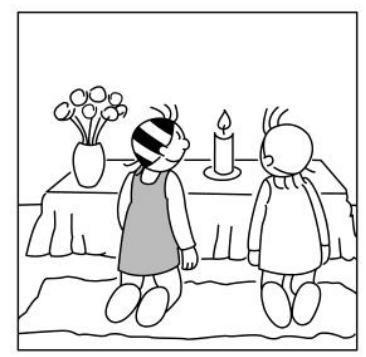

to think about God
Benevolence

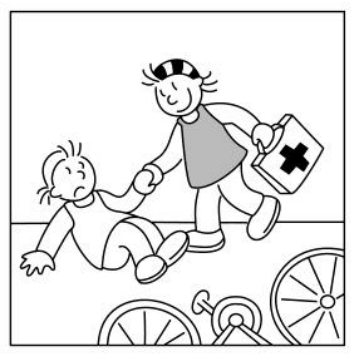

to hep others
Achievement

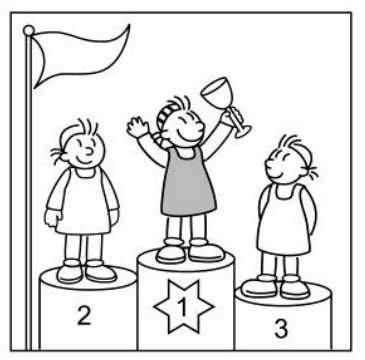

to be best
Self-Direction

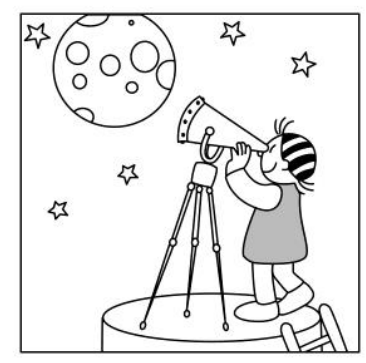

to discover new things

Pilot study 2. The Picture-Based Value Survey for Children (PBVS-C) was applied to 25 students (male: 11 and female: 14) from first to fifth grades. The students' ages ranged from 7 to 11 (X:8.96, sd: 1.48). The picture TR-1 in 'Assessing Children's Values, The Picture-Based Value Survey for Children (PBVS-C), developed by Döring (2008), was not correctly understood by children in the previous preliminary study (it was perceived as "they are eating, lights are off and so on by the Turkish children instead of thinking about God). A picture that would describe "thinking about God" in Turkey was drawn dessingner. First of all, without any information about any of the values, participants were posed questions such as "what do you see in each picture, what is happening here, what is the hero doing in the picture, what is important to the hero". According to Table-1, each correct answer given by children was scored 1 point and each answer inconsistent with the pictures was scored 0 point. Data obtained suggests that the picture TR- 1 was described by 24 students as "they are praying and performing devotions. ". The picture TR- 1 re-drawn was described by one of the first-grade students alone as "they are sitting on the carpet".

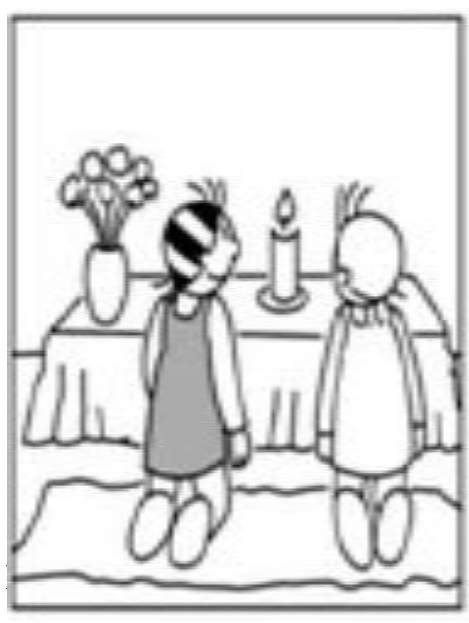




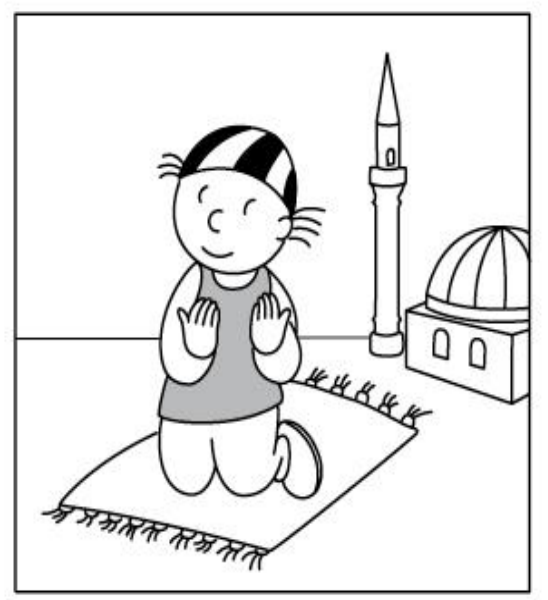

Figure 4. TR-1- Thinking about God

Main study. Permissions required to conduct the study were obtained from Denizli Provincial Directorate for National Education of Ministry of Education. The survey was applied in groups of two persons in younger age groups and of three persons in older age groups. Researchers watched a sample application from video. Then they applied the scale to the children in the direction of this sample appplication. The participants were asked whether or not they wish to participate in the study and then, they were motivated for the study. Each application continued approximately for 60 minutes. First of all, the students were asked to complete and fill in the section about demographic information. Then, the procedure was initiated after explaining what each picture represented. We were would like to put themselves in the hero's place in the picture. Firstly, they were asked to select two pictures that were the most important in the hero's life, and secondly, they were again asked to stick the stickers by selecting the two least important pictures. Thirdly, they were asked to stick the four less important pictures in order of priorities. Fourthly, they were asked to select and stick the four less trivial pictures. Fifthly, they were asked to classify the remaining pictures in order of priorities from important to unimportant.

\section{RESULTS}

\section{Structural Analysis}

The structural analysis was established on the basis of Schwartz's value model (Figure-1; Table-2). Accordingly, Multi-dimensional Scaling (MDS) analysis was analysed in two-dimension (xy). MDS is an analysis technique analysing data of a group of object based on their similarities and differences. The geometrical distance attempts to model the data as distances between the points. MDS is not only data analysis but also the modelling structure of psychological phenomena. It creates a rule for the overall similarity judgement by the dimensional difference (Borg \& Groenen, 2005: 359).

Table 2. Motivational Value Types (see, e.g., Schwartz, 1992,1994:22)

\begin{tabular}{|c|c|c|c|c|}
\hline $\begin{array}{l}\text { Value Types (and Items) } \\
\text { Central Motivational Goal }\end{array}$ & Angle & & $\begin{array}{l}\text { Coordinate on } \\
\text { the } x \text {-Axis } \\
\cos \end{array}$ & $\begin{array}{l}\text { Coordinate on } \\
\text { the } y \text {-Axis } \\
\text { sin }\end{array}$ \\
\hline Universalism UN (UN1, UN2) & 72 & & 0.31 & 0.95 \\
\hline (Benevolence BE (BE1, BE2) & 36 & & 0.81 & 0.50 \\
\hline Tradition TR (TR1, TR2) & & 0 & 1.00 & 0.00 \\
\hline Conformity CO (CO1, CO2) & 324 & & 0.81 & 0.59 \\
\hline Security SE (SE1, SE2) & 288 & & 0.31 & 0.95 \\
\hline Power PO (PO1, PO2) & & & 0.31 & 0.95 \\
\hline
\end{tabular}


Kapıkıran,N.A. \& Gündoğan,A. (2018). Assessment for children's values: Picture-based value survey for children adaptation study. International Journal of Educational Research Review,3(2),9-21.

$\begin{array}{llll}\text { Achievement AC (AC1, AC2) } & 216 & 0.81 & 0.59 \\ \text { Hedonism HE (HE1, HE2) } & 180 & 1.00 & 0.00 \\ \text { Stimulation ST (ST1, ST2) } & 144 & 0.81 & 0.59 \\ \text { Self-Direction(SD)(SD1,SD2) } & 108 & 0.31 & 0.95\end{array}$

Similar materials are located in close proximity to each other in MDS. The materials are located in a closer distance to each other as their similarities increase. The materials are located in a further distance to each other as their differences increase. It has been reported that the theory based MDS can be used in value surveys. The theory-based approach evaluates each article within the theory based on the theory tested (Döring, 2010). Each article is placed in a circle according to 10 value types. These regions have equal sizes (each is approximately stress $=.0001$, maximum 36 ). In this analysis, the PROXSCAL module in SPSS 11.5 was used (stress convergence $=.0001$, minimum iterations $=100)$. Spence \& Ogilvie, (1973)consider the Stress 1 as a loss function that provides distance-related information more widely and regarding the compliance (non-compliance) between the similar data. (As the Stress 1 value becomes smaller, similar data provides a better distance). Random similar data of the variable 0.20 is expected to be Stress 10.30 in a two-dimensional distance (Döring, 2010). In this analysis, Tucker's compliance coefficient of the materials was calculated as 0.93 and the Stress 1 score as 0.35 . So, we can state that the similarity is a little high (Figure 5). Moreover, Borg \& Groenen (2005) reported that the stress value was smaller in the empirical analyses (Döring, 2010). When the 20 value-related pictures in Figure 5 are analysed, it is seen that the distribution is coincidental and carries no resemblance to the theoretical structure. Then, the two pictures for each value were combined and the model, which was created according to the data obtained from the PBVS-C with 20 pictures in Figure-6, was given as a result of the MDS analysis. Tucker's compliance coefficient of the materials was calculated as 0.95 and the Stress 1 score as 0.30 in the current analysis. The findings showed that universalism (UN) and benevolence (BE) values were located in a completely opposite distance from each other although these values are expected to be in a close proximity to each other.

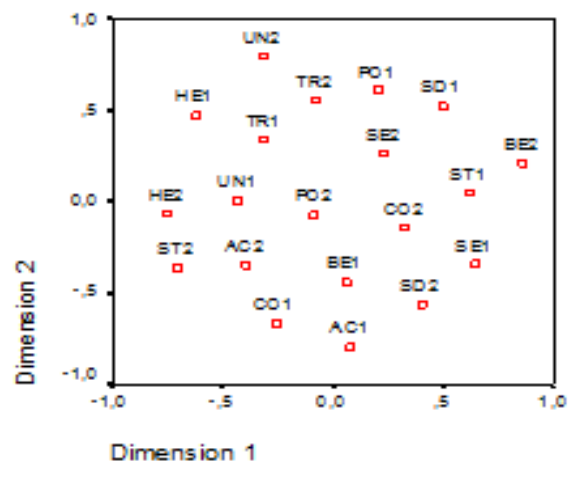

Figure 5. Starting configuration for the multidimensional scaling analyses. Stress $1=.35$ 


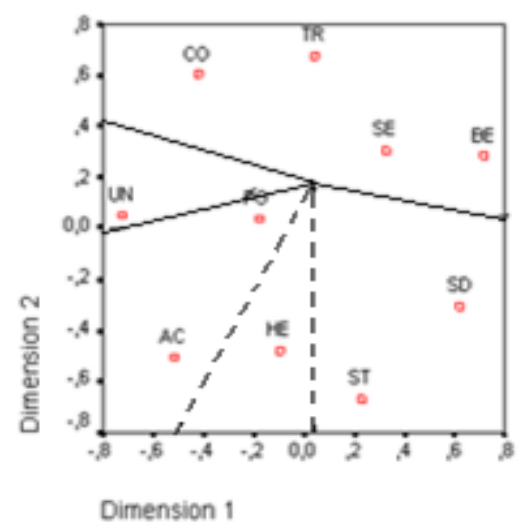

Figure 6. Starting configuration for the multidimensional scaling analyses. Stress $1=.30$

$\mathrm{UN}=$ universalism, $\mathrm{BE}=$ benevolence, $\mathrm{TR}=$ tradition, $\mathrm{CO}=$ conformity, $\mathrm{SE}=$ security, $\mathrm{PO}=$ power, $\mathrm{AC}=$ achievement, $\mathrm{HE}=$ hedonism, $\mathrm{ST}=$ stimulation and $\mathrm{SD}=$ self-direction.

At the same time, self-direction (SD) and stimulation (ST) values are located closer to conservative values but opposite angles to universalism. Similarly, self-enhancement values such as achievement (AC) and power (PO), are observed to be in opposite angles to conservative values. It is seen that values do not conform to the theoretical structure in Schwartz's structure and are settled in different locations (when hedonism values are considered as 0 degree and conservative values as 180 degree). However, it is observed that self-direction values are replaced with self-enhancement values even if this conversion is realized. At the same time, benevolence values are located in a closer proximity to conservative values while universalism is in a separate location. In this way, the structure can be separated as individual and social values. Individual values are placed in an appropriate field based on the upper classification. However, while social values are closer to universalism and self-enhancement values, values of benevolence are located closer to the values of openness to change. When the distribution of high-level values in Figure-7 on Schwartz's values model is examined, it is observed that values of self-transcendence and openness to change and values of self-enhancement and conservative are located far away from each other. While conservative (social) values are closer to values of openness to change (individual) and self-transcendence (social), they are located farthest from self-enhancement (individual) values. Pictures in this study were scored as follows: the most importanttwo pictures 5 points, important 4 pictures 4 points, averagely important 8 pictures 3 points, unimportant 4 pictures 2 points, the least important 2 pictures 1 point. As a result, the highest score of these four high level values were found to be associated with values of openness to change and the lowest score with self-enhancement.

Table 3. Descriptive Statistics for the Higher Order Value Types.

\begin{tabular}{|c|c|c|c|c|}
\hline & $\begin{array}{c}\text { Self } \\
\text { transcendence } \\
\text { (UN1, UN2, } \\
\text { BE1, BE2) }\end{array}$ & $\begin{array}{l}\text { Conservation } \\
\text { (TR1, TR2, CO1, } \\
\text { CO2, SE1,SE2) }\end{array}$ & $\begin{array}{l}\text { Self- } \\
\text { enhancement } \\
\text { (AC1, AC2, } \\
\text { PO1, PO2 }\end{array}$ & $\begin{array}{c}\text { Openness to } \\
\text { change } \\
\text { ST1, ST2, SD1, } \\
\text { SD2,HE1, HE2) }\end{array}$ \\
\hline $\mathrm{M}$ & 3.02 & 3.00 & 2.88 & 3.08 \\
\hline SD & O.53 & 0.41 & 0.53 & 0.42 \\
\hline
\end{tabular}

Note: $\mathrm{UN}=$ universalism, $\mathrm{BE}=$ benevolence, $\mathrm{TR}=$ tradition, $\mathrm{CO}=$ conformity, $\mathrm{SE}=$ security, $\mathrm{PO}=$ power, $\mathrm{AC}=$ achievement, $\mathrm{HE}=$ hedonism, $\mathrm{ST}=$ stimulation, and $\mathrm{SD}=$ self-direction 
Table 3 provides mean and standard deviations of the high level values. When compared to Döring (2010) score averages, the scores of conservative values with higher inter-score differences are closer to our scores, and the score of openness to change is higher in our study while self-transcendence values have the highest scores in Döring's score averages. The scores of the participants of this study were found closer to each other compared to the averages of the high-level values of their German peers.

Table 4. Correlations Between High Order Values Types

\begin{tabular}{|c|c|c|c|c|}
\hline & $\begin{array}{l}\text { Self } \\
\text { transcendence } \\
\text { (UN1, UN2, } \\
\text { BE1, BE2) }\end{array}$ & $\begin{array}{l}\text { Conservation } \\
\text { (TR1, TR2, CO1, } \\
\text { CO2, SE1,SE2) }\end{array}$ & $\begin{array}{c}\text { Self- } \\
\text { enhancement } \\
(A C 1, A C 2, \\
\text { PO1, PO2) }\end{array}$ & $\begin{array}{l}\text { Openness to } \\
\text { change } \\
\text { ST1, ST2 } \\
\text { HE1, HE2) }\end{array}$ \\
\hline 1 & - & $-.55^{* *}$ & $-.27^{* *}$ & $-.19^{* *}$ \\
\hline 2 & - & - & $-.39^{* *}$ & $-.38^{* *}$ \\
\hline 3 & - & - & - & $-.19^{* *}$ \\
\hline
\end{tabular}

Note: $\mathrm{UN}=$ universalism, $\mathrm{BE}=$ benevolence, $\mathrm{TR}=$ tradition, $\mathrm{CO}=$ conformity, $\mathrm{SE}=$ security, $\mathrm{PO}=$ power, $\mathrm{AC}=$ achievement, $\mathrm{HE}=$ hedonism, $\mathrm{ST}=$ stimulation, and $\mathrm{SD}=$ self-direction

${ }^{* *} 0.01$

When the correlations between the values are examined, it is seen that values of self-direction have a lower negative correlation with self-enhancement values as individualistic values as well as selftranscendence values as social values. The highest negative correlation is between conservative values and self-transcendence values. In other words, these two social values are considered more distant from each other. The cause of this distance is universalism rather than benevolence. This difference is indicated in Figure 7.

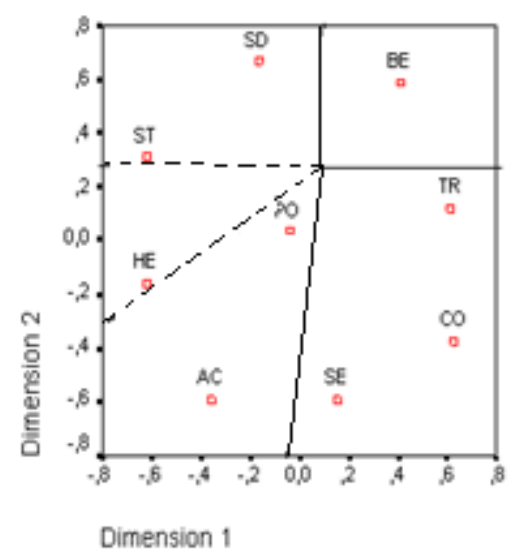

Figure 7. Starting configuration for the multidimensional scaling analyses. Stress $1=.28$

Note: $\mathrm{UN}=$ universalism, $\mathrm{BE}=$ benevolence, $\mathrm{TR}=$ tradition, $\mathrm{CO}=$ conformity, $\mathrm{SE}=$ security, $\mathrm{PO}=$ power, $\mathrm{AC}=$ achievement, $\mathrm{HE}=$ hedonism, $\mathrm{ST}=$ stimulation, and $\mathrm{SD}=$ self-direction $\quad{ }^{* *} 0.01$ 
Then, data are analysed again by excluding this data because values regarding universalism were reported to have been located in an opposite region. According to the result of multi-dimensional scaling analysis (MDS), Tucker's compliance coefficient of the pictured-materials was calculated 0.95 and the Stress1 value as 0.28 . It has been reported in this analysis that all the values have been settled with proper angles and in proper locations in accordance with Schwartz's values model when universalism is excluded (Figure 7). As a result, universalism appears as a separate value and benevolence appears to be close to conservative values.

\section{DISCUSSION}

In the current study the Picture-Based Value Survey for Children (PBVS-C)(Döring, 2008) was adapted to Turkish. Some self-report studies were performed to determine children's values (Bilsky, Niemann, Schmitz \& Rose, 2005; Döring, 2010). The value structure that is similar in the studies conducted with adults has been found to be applicable also to children. Then, the study for children to identify with pictures was performed (Döring, 2008; Döring, 2010), and it was reported that value types and motivation resources also with the pictures were similar to adults. Picture-based measurements eliminate limitations of self-report measurements for children such as reading comprehension, reading etc. and finding the appropriate option by reading and understanding. In this study, it was thought that a measuring tool for assessing children's values could be used to determine the values of Turkish children by using stickers because it was considered that such stickers would be more practical to determine the children's values and would motivate the children's participation in the study.

Students from three different schools have been reached for the study. This study aimed to determine that the survey applicable to the German peers would also be applicable to Turkish children. As a result of preliminary studies, only the picture TR1 of the 20 pictures (thinking about God) was perceived differently because of religion differences.

The applicability of the scale was determined with a preliminary study by adding a new picture specific to Turkish culture. Then, compliance of the data obtained with Schwartz's values model $(1992,1994)$ was achieved in the main study through Multidimensional Scaling (MDS) (Borg \& Groenen, 2005). It was reported that the data obtained was not specific to a certain region in modelling the pictures in the first analyses (Figure 5). Then, analyses were carried out by collecting two pictures in line with the 20 pictures and 10 value categories. As a result of this analysis, the value of universalism was reported to be in an opposite position to the social values while it was expected to be closer to the value of benevolence. The value of benevolence was found to be closer to the conservative values. However, it is observed that other values are not positioned in appropriate angles geometrically (Fig. 6)

So, when the value of universalism in a different position is excluded, all of the other high-level values confirm Schwartz's values model in proper angles. As can be seen in Figure 7, universalism is perceived differently. The highest negative correlation in the correlations between the values in Table 4 has been recorded between the social values (self-transcendence and conservative values. The lowest negative correlation was found between the values of openness to change and self-enhancement and selftranscendence. Yet, in the theoretical structure, openness to change and conservative values are the values farthest to the values such as self-transcendence and self-enhancement (Schwartz, 1992, 1994, 2009; Schwartz, et al., 2001).

In other words, the higher negative correlation of conservative values with self-transcendence values, which are closer to the individual values, indicates that these values are positioned in opposite regions (Table 4). The highest score has been reported to be associated with openness to change while the lowest score with self-enhancement value when the averages of the high-level values are examined (Table 3). Döring (2010) reported that the highest-score in the German children was recorded in self-transcendence value and the lowest score was similar to the score of Turkish children and the scores of conservative values of the two communities were very close to each other. While the difference between the scores of all highlevel value types of the German children was greater, the scores of Turkish children were found to be closer to each other. It is interesting that the German children have higher levels of self-transcendence values 
although the German society is an individualistic society and the Turkish children have higher levels of selfdirection values despite the Turkish society has a relatively more collectivistic culture. However, similar scores of conservative values and lower scores of self-enhancement values in the both communities may highlight the similarity between these two communities. Studies in the literature seem to support this similarity (Schwartz \& Bardi, 2001).

Higher levels of self-transcendence values in the German population as an individualistic society may be associated with the country's democratic structure. Similar results were reported in studies conducted with young and adult people(Caprara, Schwartz, Capanna, Vecchione \& Barbaranelli, 2006; Sagiv \& Schwartz, 1995; Schwartz, Caprara, \& Vecchione, 2010; Piurko, Schwartz \& Davidov, 2011).

The literature reports that values of openness to change are higher in more democratic societies(Caprara, et al., 2006; Sagiv \& Schwartz, 1995; Schwartz, et al., 2010). For example, individuals more conservative in the Eastern Europe were found to be more open to change while more liberal individuals were open to change in the Western Europe (Thorisdottir, Jost, Liviatan \& Shrout, 2007).

\section{CONCLUSION AND SUGGESTIONS}

In the end of the study showed that the scale being developed based on Schwartz's theoretical model featured different dimensions for some of the values; e.g. different results were obtained for the "universalizm" dimension. Children make moral judgements from the very early periods of their lives, so their values begin to develop at quite early ages.

The study contains several limitations. One of them was that the study was based on the participants only from three schools in the city of a province in the Aegean Region. The schools were selected from three different locations in the city centre. The study covered only the state schools and no private school was included. The second limitation of the study was that only the construct validity of this measuring tool was examined. The third limitation of the study was that the scale was applied in small groups.

Future studies will enable composition of the scale with results of different sampling groups in developmental dimension as well as educational process and provide more accurate information on the value structure of children in the Turkish society. The scale will enable performance of studies for determining the correlation of the children's values with many variables such as, in particular, attachment styles, self-concept, parental attitudes. It is known that children make moral judgements from the very early periods of their lives, so their values begin to develop at quite early ages. With this measuring tool, both the relation with different variables through cross-sectional and values from school ages to further periods through longitudinal studies and life experiences that lead to change can be determined.

\section{REFERENCES}

Balliet, D. Joiremon, J. Daniels, D. \& George-Falvy, J. (2008). Empathy and the Schwartz value system: A test of an integrated hypothesis. Individual Differences Research, 6 (4), 269-279.

Bilsky, W., \& Schwartz, S. H. (1994). Values and personality. European journal of personality, 8(3), 163-181.

Bilsky, W. Niemann, F. Schmitz, J., \& Rose, I. (2005, July). Value structure at an early age: cross-cultural replications. In Facet theory: Design, analysis and applications. Proceedings of the 10th International Facet Theory Conference in Rome (pp. 241-248). Prague, Czech Republic: Agentura Action M.

Borg, I., \& Groenen, P. J. F. (2005). Modern multidimensional scaling: Theory and application (2nd ed.). New York, NY: Springer.

Bubeck, M., \& Bilsky, W. (2004). Value structure at an early age. Swiss Journal of Psychology, 63 (1), 31-41.

Caprara, G. V., Schwartz, S.H., Capanna, C., Vecchione, M., \& Barbaranelli, C. (2006). Personality and politics: Values, traits, and political choice, Political Psychology,. 27 (1),1-28.

Casas, F., Figuer, C., Gonzalez, M., \& Malo, S. (2007). The value adolesents aspire to, their wellbeing and the values parents aspire to for their children. Social Indicator Research. 84(3), 271-290. 
Davidov, E., \& De Beuckelaer, A. (2010). How harmful are survey translations? A test with Schwartz's human values instrument. International Journal of Public Opinion Research , 22(4), 487-510.

Dilmaç, B., Deniz, M. \& Deniz, M. E. (2009). Üniversite öğrencilerinde öz anlayış ile değer tercihlerinin incelenmesi. Değerler Eğitimi Dergisi, 7(8), 9-24.

Dirilen, Ö. (2006). Relationship between values and culture: A comparison of central Asain and Turkish university students. Master Thesis. METU. Ankara.

Döring, A. K. (2010). Assessing children's values: An exploratory study. Journal of Psychoeducational Assessment. 28(6), 564-577.

Döring, A. K. Blauensteiner, A., Aryus, K., Drögekamp, K., .\& Bilsky, W. (2010). Assessing values at an early age: The picture-based value survey for children (PBVS-C) Journal of Personality Assessment, 92(5), $439-448$.

Döring, A. K. (2008). Assessment of children's values: The development of a picture-based instrument. Doctoral Dissertation. Münster University, Münster, Germany.

Göregenli, M. (1995). Kültürümüz açısından bireycilik-toplulukçuluk eğilimleri: Bir başlangıç çalışması. (Individualism collectivism orientations in the Turkish culture: A preliminary study). Journal of Turkish Psychology, 10(35), 1-14.

Gümüş, Ö.D. (2009). Kültür, değerler, kişilik ve siyasal ideoloji arasındaki ilişkiler: kültürlerarası bir karşılaştırma (Türk-ABD). [Culture, values, personality, and the relationship between political ideology: A cross-cultural comparison (Turkey-USA), PhD Thesis.]. Doktora Tezi. A.Ü. Sosyal Bilimler Enstitüsü. Ankara.

İmamoğlu, E. O. \&Katipoğlu-Akgün, Z. (2004). Self-construals and values in different cultural and socioeconomic contexts. Genetic, Social, and General Psychology Monographs, 130(4), 277-306.

İmamoğlu, E. O. (2003). Individuation and relatedness: Not opposing, but distinct and complementary. Genetic, Social, and General Psychology Monographs, 129, 367-402.

Kağıtçıbaşı, Ç. (1996). The autononomous-relational self: A new synthesis. European Psychologist,1(3),180-186

Knafo, A., \& Schwartz, S. H. (2001). Value socilaziton in family of Israil-born and Soviet-born adolesents in Israil. Journal of Cross-cultural Psychology, 32(2), 213-228.

Knafo, A. (2003). Contexts, relationship quality, and family value socialization: The case of parent-school ideological fit in Israel. Personal Relationships, 10(3), 371-388.

Knafo, A. \& Schwartz, S. H. (2003). Parenting and adolescents'accuracy in perceiving parental values. Child Development, 74(2), 595-611.

Knafo, A., \& Schwartz, S. H. (2004).Identity formation and parent-child value congruence in adolescence. British Journal of Developmental Psychology, 22(3), 439-458.

Knafo, A., \& Assor, A. (2007). Motivation for agreement with parenthal values: Desirable when autonomous, problematic when controlled. Motivation and Emotion, 31(3), 232-245.

Knafo, A., \& Spinath, F. M. (2011). Genetic and environmental influences on girls' and boys' gender-typed and gender-neutral values. Developmental Psychology, 47(3), 726-731.

Laible, D., Eye, J., \& Carlo, G. (2008). Dimensions of conscience in mid-adolescence: Links with social behavior, parenting, and temperament. Journal of Youth and Adolescence, 37(7), 875-887.

Nunner-Winkler, G. (2007). Development of moral motivation from childhood to early adulthood. Journal of Moral Education, 36(4), 399-414.

Padilla-Walker, L. M. (2007). Characteristics of mother-child interactions related to adolescents' positive values and behaviors. Journal of Marriage and Family, 69(3), 675-686. 
Piurko, Y., Schwartz, S. H. Davidov, E. (2011). Basic personal values and the meaning of left-right political orientations in 20 countries. Political Psychology, 32 (4), 537-561.

Sagiv, L., \& Schwartz, S. H. (1995). Value priorities and readiness for out-group social contact. Journal of Personality and Social Psychology, 69(3), 437-448.

Schwartz, S.H. \& Bilsky, W. (1990). Toward a theory of the universal content and structure of values. Extensions and cross-cultural replicators. Journal of Personality and Social Psychology, 58(5), 878-891.

Schwartz, S. H. (1992). Universals in the content and structure of values: Theoretical advances and empirical tests in 20 countries. Advances in experimental social psychology, 25(1), 1-65.

Schwartz, S.H. (1994). Are there universal aspects in the structure and contents of human values? Journal of Social Isues. 50(4), 19-45.

Schwartz, S.H. (1999). A theory of cultural values and some impilications. Applied Psychology: An International Review, 48(1), 23-47.

Schwartz, S. H., Sagiv, L., \& Boehnke, K. (2000). Worries and values. Journal of Personality 68 (2), 309-346.

Schwartz, S.H., \& Sagie, G. (2000). Value consensus and importance: A cross national study. Journal of CrossCultural Psychology, 31(4), 465-497.

Schwartz, S. H., \& Bardi, A. (2001).Value hierchies across culture: Taking a similirities perspective .Journal of Cross-Cultural Psychology, 32(3), 268-290.

Schwartz, S. H., Melech, G., Lehmann, A., Burgess, S., Harris, M., \& Owens, V. (2001). Extending the crosscultural validity of the theory of basic human values with a different method of measurement. Journal of Cross-Cultural Psychology, 32(5), 519-542.

Schwartz, S. H. (2006). Basic human value: An overview. (Les valeurs de base de la personne, theorie, mesures et applications.) Revue francaise de Sociologie, 4(2), 249-288.

Schwartz, S. H. (2009). Basic human values. Cross-national comparison seminar on the quality and comparability of measures for constructs in comparative research. Methods and Applications. Bolzano, Italy, June, 10-13.

Schwartz, S. H., \& Rubel-Lifschitz, T. (2009). Cross-national variation in the size of sex differences in values: Effects of gender equality. Journal of Personality and Social Psychology, 97(1), 171-185.

Schwartz, S. H., Caprara, G. V., \& Vecchione, M. (2010). Basic personal values, core political values, and voting: A longitudinal analysis. Political Psychology, 31(3), 421-452.

Struch, N., Schwartz, S. H., \& van der Kloot, W. A. ( 2002). Meanings of basic values for women and men: A cross-cultural analysis. Personalityand Social Psychology Bulletin, 28(16),16-28.

Thorisdottir, H., Jost, J. T., Liviatan, I., \& Shrout, P. E. (2007). Psychological needs and values underlying leftright political orientation: Cross-national evidence from Eastern and Western Europe. Public Opinion Quarterly, 71(2), 175-203.

Wray-Lake, L., Flanagan, C. A., \& Maggs, J. L. (2012). Socialization in context: Exploring longitudinal correlates of mothers' value messages of compassion and caution. Developmental psychology, 48(1), 250-256.

Yılmaz, E., Avşaroğlu, S., \& Deniz, M. (2010). An investigation of teacher candidates'value preferences. Procedia: Social and Behavioral Sciences. 2(2), 4943-4948.

Note: We thank Dr. Döring for giving the survey permission and the financial support of drawing one picture 